\title{
Etravirine Induced Severe Hypersensitivity Reaction and Fulminant Hepatitis: A Case Report and Review of the Literature
}

\author{
Linda Nabha1*, Gayle P. Balba1, Carmelita Tuazon ${ }^{2}$ and Princy N. Kumar ${ }^{1}$ \\ ${ }^{1}$ Division of Infectious Diseases, Georgetown University Hospital, Washington, D.C, USA \\ ${ }^{2}$ Department of Medicine, George Washington University Hospital, Washington, D.C, USA
}

\begin{abstract}
We report the first published case of etravirine induced hypersensitivity reaction leading to fulminant hepatic failure in a 49-year-old female patient with Human Immunodeficiency Virus. She presented with a life threatening rash and end stage organ damage requiring intensive care unit supportive care. Liver biopsy supported the diagnosis of drug-induced hypersensitivity. The patient recovered after withdrawal of etravirine and the use of systemic corticosteroids. The authors describe etravirine drug hypersensitivity as a clinically important reaction and that early recognition can improve survival.
\end{abstract}

Keywords: Human immunodeficiency virus; Hepatitis; Antiretroviral therapy; Drug hypersensitivity; Etravirine

\section{Introduction}

Etravirine is a second generation non-nucleoside reverse transcriptase inhibitor (NNRTI) used in treatment-experienced patients or patients with drug resistant Human Immunodeficiency Virus (HIV). In a pooled analysis of phase III trials, etravirine demonstrated a favorable safety profile compared with control with the exception of rash reported more frequently with etravirine than placebo, $21 \%$ versus $12 \%$, respectively $[1,2]$.

Despite etravirine's safety profile in clinical trials, several post-marketing reports of severe skin reactions which include hypersensitivity reactions resulting in hepatic failure have recently been identified. As a result, Janssen Therapeutics, formerly Tibotec Pharmaceuticals, and the Food and Drug Administration issued a letter informing healthcare professionals of such findings $[3,4]$. To date, we report the first case of a life threatening hypersensitivity reaction to etravirine resulting in rash and fulminant hepatic failure.

\section{Observation}

A 49-year-old African American woman with HIV and resolved hepatitis B had been taking highly active antiretroviral therapy (HAART) for over 10 years. She had adverse reactions to indinavir, nelfinavir, abacavir, efavirenz, nevirapine and tenofovir and her antiretroviral therapy (ART) had been limited to didanosine and stavudine. With the approval of etravirine and raltegravir, the patient's ART was changed to etravirine $200 \mathrm{mg}$, raltegravir $400 \mathrm{mg}$, and lopinavir/ ritonavir $400 \mathrm{mg} / 100 \mathrm{mg}$ each given twice daily. Her baseline CD4 count was 216 cells $/ \mathrm{mL}$ and her viral load was 902 copies $/ \mathrm{mL}$ prior to the initiation of this regimen. Liver function tests, complete blood counts, and electrolytes were within normal limits. She was not on any other medications or herbal supplements. She also denied alcohol use. Three weeks after beginning her new HAART, she developed a diffuse maculopapular rash. Despite discontinuation of the antiretroviral therapy, her rash progressed with involvement of her entire body and she developed fever, jaundice, emesis, and diarrhea. Physical examination revealed a febrile, encephalopathic and severely jaundiced patient with a diffuse maculopapular rash on the face, chest, abdomen, and extremities sparing her mucous membranes, with early signs of desquamation. She had hepatomegaly and right upper quadrant tenderness.
Laboratory studies on admission revealed a white blood cell count of $13.3 \times 10^{3} / \mu \mathrm{L}$ with $10 \%$ eosinophils (normal, $0-5 \%$ ) and absolute eosinophils $1.3 \times 10^{3}$ cells $/ \mu \mathrm{L}$ (normal, $0-0.65 \times 10^{3}$ cells $/ \mu \mathrm{L}$ ). Liver enzyme peak values were aspartate transaminase $2364 \mathrm{IU} / \mathrm{L}$, alanine transaminase $1174 \mathrm{IU} / \mathrm{L}$, total bilirubin $19.4 \mathrm{mg} / \mathrm{dL}$, and INR 3.05 on her day of hospitalization. Acute hepatitis panel for Hepatitis A, B, and $\mathrm{C}$ were negative. Hepatitis B Viral DNA PCR was undetectable and Hepatitis C RNA PCR was less than $50 \mathrm{IU} / \mathrm{mL}$. HIV-1 RNA quantitative PCR was less than 48 copies/mL. A urine toxicology screen was negative for acetaminophen. Except for hepatomegaly, an abdominal ultrasound was unremarkable for liver lesions and showed a patent hepatic vasculature. A transjugular liver biopsy showed confluent multiacinar hepatic necrosis with portal mixed inflammatory infiltrates including eosinophils, activated lymphocytes and plasma cells suggestive of a drug induced etiology (Figure 1).

She was considered for liver transplant due to fulminant and worsening hepatic failure. She was managed in the intensive care unit with aggressive fluid-electrolyte management, empiric antibiotics, rifaximin and lactulose. However she only improved after intravenous methylprednisolone was administered. After which, she made a slow but steady recovery. Because of her significant improvement, she did not need a liver transplant and was discharged home after fifteen days of hospitalization. Her liver function tests normalized six weeks after etravirine was discontinued.

\section{Discussion}

Our case report underscores the importance of recognizing drug induced hypersensitivity syndrome (DHS) from etravirine use. DHS,

*Corresponding author: Linda Nabha, Division of Infectious Diseases, Georgetown University Hospital, Washington DC 20007, 3800 Reservoir Road, NW, 5-PHC, USA, Tel: 202-444-0091; Fax: 1-877-665-8072; E-mail: Linda.Nabha@gunet.georgetown.edu

Received October 20, 2011; Accepted January 06, 2012; Published January 10 2012

Citation: Nabha L, Balba GP, Tuazon C, Kumar PN (2012) Etravirine Induced Severe Hypersensitivity Reaction and Fulminant Hepatitis: A Case Report and Review of the Literature. J AIDS Clinic Res S2:005. doi:10.4172/2155-6113.S2-005.

Copyright: @ 2012 Nabha L, et al. This is an open-access article distributed under the terms of the Creative Commons Attribution License, which permits unrestricted use, distribution, and reproduction in any medium, provided the original author and source are credited. 


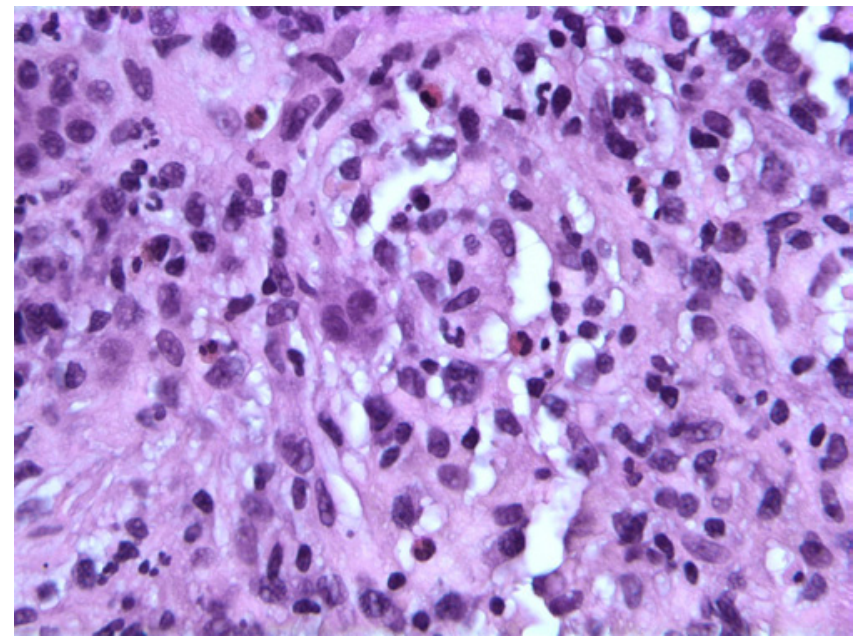

Figure 1: A hepatic biopsy showing confluent multi acinar hepatic necrosis with portal mixed inflammatory infiltrates including eosinophils, activated lymphocytes and plasma cells suggestive of drug induced etiology.

also known as drug rash with eosinophilia and systemic symptoms, is characterized by exfoliative dermatitis, fever and potentially life threatening end organ damage $[5,6]$. Severe DHS has been reported in less than $2 \%$ of all HIV-infected individuals treated with NNRTIs and most commonly described with nevirapine use $[7,8,9]$. In clinical practice, severe cutaneous reactions appear to be less common with efavirenz than with nevirapine. The incidence of DHS in efavirenz is $0.14 \%$ in all studies [10]. Rilpivirine licensure was recently approved in May, 2011. To date, no cases of rilpivirine associated DHS have been reported.

The primary cause of mortality in DHS is fulminant hepatic failure, occurring between 1 and 6 weeks after the initiation of drug therapy and often necessitates liver transplant [11,12]. Our patient presented with an exfoliative rash, eosinophilia, and hepatic failure approximately 3 weeks after initiation of etravirine. Histopathologic findings on liver biopsy associated with DHS include necrosis, cholestasis, and eosinophilic infiltration, as was seen in our case [5].

DHS caused by nevirapine has been well documented in the literature. Historically, this adverse reaction has been associated in women with CD4 counts greater than 250 cells $/ \mathrm{mm}^{3}$ and men with CD4 counts greater than 400 cells $/ \mathrm{mm}^{3}$. Liver biopsy results in these patients have found eosinophilic and lymphocytic infiltration consistent with an immune mediated mechanism and frequently necrosis. Based on the case reports of nevirapine induced liver injury, the median onset of symptoms is typically 14 days and the median time to improvement is 21.5 days $[8,9,12]$. Our case is similar to DHS caused by nevirapine in several ways. First, our patient presented with severe rash and fulminant hepatic failure 21 days into initiation of her etravirine based regimen. Second, her liver biopsy was similar to the pattern seen with nevirapine hepatotoxicity. Finally, her liver function tests normalized within 6 weeks of etravirine withdrawal, which is similar to the timeframe of resolution of nevirapine induced hepatitis. Our patient previously had a rash to both the NNRTIs, efavirenz and nevirapine without hepatoxicity. It remains to be elucidated if adverse reactions from prior exposure to NNRTIs poses a risk factor for DHS and should not be overlooked.

The Roussel Uclaf Causality Assessment Method of the Council for International Organizations of Medical Sciences (RUCAM/CIOMS) is one of the most widely used scales for establishing a causal relationship between the offending drug and liver damage. Application to our case showed a causality of this adverse drug reaction using the RUCAM/ CIOMS scale of seven or "probable" adverse reaction $[13,14]$.

Our patient was also on raltegravir and lopinavir/ritonavir. Raltegravir is generally a well-tolerated HIV-1 integrase inhibitor. A review of the current literature through PubMED shows limited data on the toxicity and side effects of this medication. A common adverse effect with raltegravir use is elevated alkaline phosphatase levels, which can range between 2.6 to five times the upper limit of normal $[15,16]$. Elevated creatinine phosphokinase levels in association with myopathy and rhabdomyolysis have also been reported [17]. In November 2011, the FDA added rash and hypersensitivity reaction to the warning and precaution section of raltegravir [16]. However our patient was rechallenged with raltegravir after hospital discharge and has been on raltegravir for over one year without any adverse reaction. Lopinavir/ ritonavir combination has been associated with mild to moderate hepatic impairment and this is usually limited to patients with Hepatitis $\mathrm{C}$ viremia and baseline hepatic insufficiency [18]. Lopinavir/ritonavir has rarely been associated with drug hypersensitivity reaction. We excluded lopinavir/ritonavir as the offending drug in our patient as she tolerated it in the past without any rash or liver abnormalities.

Our case was one of first post-licensure reports of etravirine induced hypersensitivity reaction with hepatic failure. A request to Janssen Therapeutics for details on the additional reported hypersensitivity cases presented in the etravirine investigator's brochure was declined at this time. We searched medline through PubMed using the words etravirine, hypersensitivity, Stevens Johnson syndrome and toxic epidermal necrolysis to look for cases of hypersensitivity reaction and end organ failure. To the best of our knowledge, this is the first published case report of etravirine induced drug hypersensitivity reaction. If not recognized with prompt removal of the offending agent, DHS can lead to significant morbidity and mortality. Early administration of intravenous corticosteroids may be beneficial and may improve patient outcome $[11,19]$.

\section{Acknowledgements}

We thank Dr. Mary Furlong and Dr. Maria Romero for assistance with pathology pictures.

\section{References}

1. Katlama C, Clotet B, Mills A, Trottier B, Molina JM, et al. (2010) Efficacy and safety of etravirine at week 96 in treatment-experienced HIV type-1-infected patients in the DUET-1 and DUET-2 trials. Antivir Ther 15: 1045-1052.

2. Madruga JV, Cahn P, Grinsztejn B, Haubrich R, Lalezari J, et al. (2007) Efficacy and safety of TMC125 (etravirine) in treatment-experienced HIV-1-infected patients in DUET-1: 24-week results from a randomized, double-blind, placebocontrolled trial. Lancet 370: 29-38.

3. Tibotec Therapeutics (2009) Letter: Safety update to the Severe Skin Reactions WARNINGS AND PRECAUTIONS section (5.1) of the INTELENCE. Highlights of prescribing information.

4. U.S. Food and Drug Administration (2009) MedWatch The FDA Safety Information and Adverse Event Reporting Program, Intelence (etravirine).

5. Bocquet H, Bagot M, Roujeau JC (1996) Drug-Induced Pseudolymphoma and Drug Hypersensitivity Syndrome (Drug Rash with Eosinophilia and Systemic Symptoms: DRESS). Semin Cutan Med Surg 15: 250-257.

6. Rojeau J (2005) Clinical heterogeneity of drug hypersensitivity. Toxicology 209 123-129.

7. Chu KM, Boulle AM, Ford N, Goemaere E, Asselman V, et al. (2010) Nevirapine-Associated Early Hepatotoxicity: Incidence, Risk Factors, and Associated Mortality in a Primary Care ART Programme in South Africa. PLoS One 5: e9183. 
Citation: Nabha L, Balba GP, Tuazon C, Kumar PN (2012) Etravirine Induced Severe Hypersensitivity Reaction and Fulminant Hepatitis: A Case Report and Review of the Literature. J AIDS Clinic Res S2:005. doi:10.4172/2155-6113.S2-005.

8. Davis M, Shearer WT (2008) Diagnosis and Management of HIV Drug Hypersensitivity. J Allergy Clin Immunol 121: 826-832.

9. Patel SM, Johnson S, Belknap SM, Chan J, Sha BE, et al. (2004) Serious adverse cutaneous and hepatic toxicities associated with nevirapine use by non-HIV-infected individuals. J Acquir Immune Defic Syndr 35: 120-125.

10. Dona C, Soriano V, Barreiro P, Jiménez-Náchera I, González-Lahoz J (2000) Toxicity associated to efavirenz in HIV-infected persons enrolled in an expanded access program. Med Clin (Barc) 115: 337-338.

11. Borras-Blasco J, Navarro-Ruiz A, Borrás C, Casterá E (2008) Adverse cutaneous reactions associated with the newest antiretroviral drugs in patients with human immunodeficiency virus infection. J Antimicrob Chemother 62: 879888.

12. Ogedegbe AO, Sulkowski MS (2003) Antiretroviral-associated liver injury. Clin Liver Dis 7: 475-499.

13. Miljkovic MM, Dobric S, Dragojevic-Simic V (2011) Consistency between causality assessments obtained with two scales and their agreement with clinical judgments in hepatotoxicity. Pharmacoepidemiol Drug Saf 20: 272-285.
14. Benichou C, Danan G, Flahault A (1993) Causality assessment of adverse reactions to drugs--II. An original model for validation of drug causality assessment methods: case reports with positive rechallenge. J Clin Epidemiol 46: $1331-1336$

15. Fleischbein E, O'Brien J, Martelino R, Fenstersheib M (2008) Elevated alkaline phosphatase with raltegravir in a treatment experienced HIV patient. AIDS 22: 2404-2405.

16. U.S. Food and Drug Administration (2009) MedWatch The FDA Safety Information and Adverse Event Reporting Program, Isentress (raltegravir).

17. Croce F, Vitello P, Dalla Pria A, Riva A, Galli M, et al. (2010) Severe raltegravirassociated rhabdomyolysis: a case report and review of the literature. Int J STD AIDS 21: 783-785

18. Sulkowski M (2004) Drug-Induced Liver Injury Associated with Antiretrovira Therapy that Includes HIV-1 Protease Inhibitors. Clin Infect Dis 38: S90-S97.

19. Bohan KH, Mansuri TF, Wilson NM (2007) Anticonvulsant hypersensitivity syndrome: implications for pharmaceutical care. Pharmacotherapy 27: 14251439 